\title{
Editorial
}

\section{ANESTESIA E INVESTIGACIÓN EN CHILE}

\author{
"La ciencia es el alma de la prosperidad de las naciones y la fuente de todo progreso."
}

Louis Pasteur

Desde el punto de vista histórico la investigación nace no solo de la curiosidad natural del ser humano, sino que también como una forma de buscar solución a un sinfín de necesidades que se le presentan a la sociedad a lo largo de su evolución.

Los científicos son los depositarios del conocimiento histórico y por lo tanto tienen acceso a información "privilegiada" en la que se sustentan las raíces de los avances tecnológicos de la sociedad, a partir del cual se van intentando resolver inquietudes y problemas comunes de la gente.

Se genera por tanto una simbiosis entre la sociedad y la comunidad científica que es fundamental para ir mejorando la forma de vida de los pueblos. Sin embargo, en Chile en alguna parte perdimos el rumbo y en este momento se podría decir que la investigación en nuestro país, es como la niña fea del baile, aquella que nadie toma mucho en cuenta.

Cuando me pidieron colaborar con este editorial me preguntaron de que forma se podían buscar soluciones para incentivar la investigación en anestesia en nuestro país, creo que hay que ir más allá y comprender también de que forma podemos llevar la investigación de vuelta a la sociedad en distintos ámbitos del quehacer nacional, es decir volver a generar la simbiosis.

En Chile al igual que en todo el mundo se vive una era en que los conocimientos avanzan en forma tan vertiginosa que la comunidad científica quedó aislada del común de la gente; en este momento la gente común es "analfabeta" desde el punto de vista de las corrientes de pensamiento y de la investigación de vanguardia.

El primer paso para solucionar la carencia de investigadores en Chile es contar con gente deseosa de seguir esta carrera. Volver a encender la llama de la curiosidad en la población; no sacamos nada con tener millones de dólares a nuestra disposición y los equipos más sofisticados si somos incapaces de pensar, de cuestionarnos el mundo que nos rodea 0 de preguntarnos de qué forma podemos resolver un problema.
De los 34 países que componen la OCDE, Chile y México son los dos países que menos porcentaje de su PIB invierten en investigación. En Chile contamos con menos de 800 investigadores por cada millón de habitantes, mientras que en Dinamarca existen más de 5.600 investigadores por cada millón de habitantes.

Creo que parte de la solución debiese partir por modificar nuestro sistema educativo y la forma de entregar conocimientos a los niños aprovechando algo tan valioso y natural como su curiosidad. Hoy los niños van al colegio a memorizar, pero generalmente no se les enseña a cuestionarse el mundo que los rodea. Las respuestas están sobre el pizarrón y hay pocas posibilidades de discutir o plantearse los problemas desde otro punto de vista.

La educación científica en la mayoría de los colegios tampoco está enfocada a preparar profesionales que se desempeñen en el ámbito de la investigación. Los profesores que enseñan esas asignaturas generalmente nunca han trabajado en un laboratorio, ni manejan el lenguaje utilizado en las publicaciones habituales, por lo tanto no pueden enseñar a sus alumnos a realizar una verdadera búsqueda bibliográfica o a analizar si un "paper" es de buena calidad. Esos estudiantes al entrar a la universidad se ven enfrentados a una realidad distinta, a un lenguaje desconocido y muchas veces ininteligible.

Se puede decir que uno de los pilares fundamentales de toda universidad es el desarrollo de la investigación. Y aquí tenemos otra brecha gigantesca, las llamadas "universidades tradicionales", que de algún modo son líderes en la formación de profesionales que se desempeñan en el área científica, tampoco están realizando bien su labor. Al menos en el área de ciencias de la salud, la pasada por los laboratorios es puramente formal, realizando experimentos archisabidos y pasos prácticos en los cuales las técnicas de ingeniería genética y biomedicina se ven pasar a lo lejos. Cumplido el requisito de la nota, nunca más se vuelve a poner un pie en un 
laboratorio, a no ser que sea por inquietud propia del estudiante.

Creo que ese es un error fundamental, ya que la falta de motivación, de experiencia y el miedo a cómo enfrentar la investigación genera escasez de estudiantes dispuestos a seguir perfeccionándose en esa área. Esto da pie a que la mayoría de los médicos opten por una carrera cimentada en el área clínica.

Estrategias como la impulsada hace algunos años por la Universidad de Chile toman mucho valor, esta idea consistió en crear las primeras becas de postgrado en medicina, que en vez de durar tres años duraran cinco, pero donde se privilegiara una sólida formación en ciencias básicas durante dos años y luego una formación en el área clínica. De esta forma se incentiva a los profesionales a que puedan desempeñarse en forma paralela en el ámbito clínico y también en el de la investigación.

Por otro lado y tan importante como el punto anterior es la falta de recursos con que crónicamente cuenta una institución de educación superior en Chile para enfrentar el desafío de la investigación. Todos sabemos que en países desarrollados se gastan millones de dólares en avanzar en esta carrera del saber, pero al mismo tiempo sabemos que por cada vacuna, fármaco o molécula nueva descubierta se ganan millones de dólares en patentes y conceptos de venta.

Generalmente nos aprovechamos del fruto de la investigación que se realiza en otros países y nadie quiere arriesgar fondos para entrar en una competencia que ya parece ganada de antemano por naciones que nos llevan muchos años de delantera. Para ello se hace necesario una política de Estado que invierta en investigación y no me refiero solo a dinero, sino que también respalde a aquellas instituciones y empresarios que arriesguen dinero en dicha empresa.

Se necesita también a un sector empresarial protagonista en la construcción de un proyecto científico nacional; que se entreguen además becas de intercambio para alumnos y profesores destacados en distintos ámbitos, que se generen concursos de investigación a todo nivel. También se debe otorgar financiamiento para infraestructura de laboratorios, insumos y equipamiento.

Otra idea en este sentido, sería la de atraer laboratorios extranjeros. Transformar a Chile en un polo de atracción de la comunidad científica mundial. En este punto algo hemos hecho con la presencia de las principales universidades e institutos mundiales en el Norte Grande de nuestro país. Solo por la fortuna de tener cielos despejados y buena visibilidad y haber dado las facilidades del caso, hemos logrado participar en el desarrollo de la astronomía mundial compartiendo nuestro cielo y ellos sus costosos equipos con un beneficio mutuo.

Por otro lado la búsqueda de financiamiento puede venir de préstamos de organismos foráneos como el Banco Mundial, el BID, universidades extranjeras o de organizaciones sin fines de lucro que están muy atentas a mantener polos de desarrollo y oasis de calma en regiones del mundo dominadas por la inestabilidad.

Podemos decir que de esta forma tendríamos la gente interesada, la infraestructura adecuada y una red de apoyo para la investigación. Pero otro punto no menor es la capacidad de mantener al investigador. La Universidad, el Estado o las empresas asociadas deben entender que la preparación de un científico es larga y tiene un costo alto. Si se quiere generar corrientes de pensamiento, polos de desarrollo o generación de nuevas teorías alguien tiene que asumir el costo. Ese científico que dedicó largos años de estudio y preparación debe tener derecho a una remuneración acorde con el trabajo que realiza.

En países desarrollados la gente que se dedica a la ciencia vive y trabaja tranquila porque sabe que a fin de mes le espera un sueldo que le permite vivir en forma digna y sin sobresaltos, sabe que tiene salud asegurada y que puede costear la educación de sus hijos. Y esto vale tanto para la investigación en un laboratorio de biología molecular, para el físico teórico que trata de establecer una teoría unificada del universo, el antropólogo que estudia a la cultura Moche o el profesor de literatura que estudia añosos manuscritos en una biblioteca.

Considero que hay todavía mucho por hacer, sobretodo en nuestra especialidad. Primero, un diagnóstico real de la situación actual de la investigación en anestesiología en Chile. No tenemos un mapa que nos diga dónde y qué se está haciendo, ni contamos con instrumentos que nos permitan identificar las líneas de investigación que se están siguiendo.

Los datos publicados por SCImago Journal \& Country Rank nos dicen que a pesar de todas las dificultades y de la poca inversión, en Chile se publica bastante. Si consideramos todas las áreas del quehacer científico en cuanto a publicaciones se refiere, estamos en el lugar 44 de un total de 239 países. Si nos enfocamos en latinoamérica estamos en cuarto lugar, detrás de Brasil, México y Argentina. Esta tendencia se mantiene si nos centramos en las publicaciones científicas del área médica (20.000 publicaciones en los últimos 17 años).

Si nos enfocamos en nuestra área, es decir Anestesiología y Dolor, el año pasado se publicaron 35 
trabajos de un total de 2.122 en el área de salud, es decir un $2 \%$ del total. Parece poco, pero si lo comparamos con lo que se publicó en gigantes como Brasil o México (125 y 122 publicaciones respectivamente) cambia la perspectiva. Otro hecho que es importante destacar es que las publicaciones chilenas son consideradas las de mayor impacto en Latinoamérica debido a que tienen el mayor número de citas por paper publicado.

Creo que como resumen para implementar más y mejor ciencia en Chile, se requieren políticas transversales claras que permitan un desarrollo permanente no dependiente del gobierno de turno. Un fortalecimiento de las regiones, aprovechando las ventajas naturales de ellas (laboratorios naturales), aumento sostenido de los recursos gubernamentales a través de becas o fondos concursables, formación de centros docentes y alianzas entre los distintos centros formadores del país que permitan aprovechar mejor las fortalezas de cada uno (Centros de Excelencia Nacional en distintas áreas).

Muchas veces cuando leemos los resúmenes de los trabajos enviados al Congreso Chileno de Anestesiología quedamos admirados por su calidad. Generalmente detrás de esos datos hay mucho esfuerzo, tiempo y dinero invertido. A pesar de todas las dificultades ese investigador logró llevar a buen término su trabajo, ahora es nuestra labor que ese autor pueda continuar publicando, generando datos y lo más importante enseñar a otros como lograr investigar en Chile.

Dr. Gian Paolo Volpato Presidente del Comité Científico de SACh 